\title{
The effect of hormone, dehulling and seedbed treatments on germination and adventititious root formation in blue grama
}

\author{
RAKHSHAN ROOHI AND DONALD A. JAMESON
}

\begin{abstract}
Under usual range conditions, the time between blue grama (Bouteloua gracilis) germination and adventitious roots development is such that it is rare that both of these events occur with moist soil conditions, and seedling survival is infrequent. Establishment could be enhanced if the time between germination and adventitious root development were reduced. Dehulling followed by pretreatment of seeds with selected hormones such as indoleacetic acid reduced the time between these 2 events, and may increase the probability of successful seeding. These treatments also increased the length and number of adventitious roots during early stages of development. Water injection into the planting rows at seeding time added to the beneficial effects of seed treatment, while chemical mulching detracted from these responses.
\end{abstract}

Key Words: auxin, seedling survival, water injection, chemical mulch

When a grass seed germinates, it first develops a primary root. During early development of the seedling, adventitious roots then develop. In blue grama (Bouteloua gracilis), there is a subcoleoptile between the point of emergence of the primary root from the caryopsis and the origin of the coleoptile (Hyder 1974). The adventitious roots do not begin at the seed depth, but at a higher, and thus drier, point in the soil profile.

Blue grama is commonly known to be difficult to establish by seeding. One source of difficulty relates to the light-controlled initiation of roots at the soil surface; literature relating to to these difficulties has been reviewed earlier (Roohi et al. 1991). Another source of difficulty relates to the time required between germination and adventitious root development: adventitious roots will

Authors are senior scientific officer, National Agricultural Research Center, Islamabad, Pakistan; and professor emeritus, Department of Range Science, Colorado State University, Fort Collins. Financial support provided by $F A O$ and the Colorado State University Agricultural Experiment Station.

The authors wish to acknowledge the following: Dr. Harrison Hughes, Department of Horticulture, Colorado State University, graciously helped with the design of the laboratory studies reported here, and provided the laboratory facilities. Dr. Marvin Shoop, USDA Agricultural Research Service, provided the field facilities at the Central Plains Experimental Range. Dr. Robert Bement, consultant, provided invaluable advice on the design of the field studies.

Manuscript accepted 7 July 1990 not develop before the 3-leaf stage of development. Under usual range conditions, the time between germination and adventitious root development is such that it is rare that both of these events will occur with moist soil conditions, and seedling survival is infrequent (Coffin and Lauenroth 1990).

The study reported here used various hormone treatments to hasten germination and adventitious root development. No earlier reports of hormone treatment on blue grama or related grass species have been found, but promotion of root development with a variety of plant species has shown promising results with indoleacetic acid (IAA), 3-indole-butyric acid (IBA), 1-napthyl-acetic acid (NAA), and gibberellic acid $\left(\mathrm{GA}_{3}\right)$. The literature on hormone effects on plant growth is extensive, and only selected examples relating to monocotyledons will be cited here. Callus induction and organogenesis have been reported from hormone treatment of wheat, rye, and sorghum (Mascarenhas et al. 1975a, Mascarenhas et al. 1975b, Nakano et al. 1975). Generally, organ differentiation in cereals is initiated with weaker auxins such as IAA or NAA (Masteller and Holden 1970).

This study also tested seed priming as a means of enhancement of the growth stimulus from hormone treatments. Seed priming refers to the process of bringing seeds to a relatively high moisture content prior to planting (Heydecker et al. 1975). During this process, the seeds are soaked in an osmotic solution. The osmotic agent is normally of a high molecular weight so that it cannot pass through the cell membrane. During priming, the seeds complete phases I (hydration) and II (lag phase) of germination, and require only a favorable gradient for water uptake in order to begin radical growth (Bradford et al. 1988). Primed seeds typically germinate under a wider range of conditions than do unprimed seeds (Hegarty 1978).

Other tests in this study included water injection and chemical mulching as additional treatments to promote rapid emergence. In water injection, a small amount of water is applied to the soil at time of sowing to create a small volume of plastic soil near the seed (Hauser 1986). Bement et al. (1961) successfully used chemical mulch in blue grama seedings. 


\section{Materials and Methods}

\section{Agar Culture Studies}

Initial studies on adventitious root development were conducted in agar culture. Agar was prepared for test tubes using $6.5 \mathrm{gm}$ agar per liter of half strength MS nutrient solution (Murashige and Skoog 1962). The $\mathrm{pH}$ was adjusted to 5.7. Seeds of the Hachita variety (provided by the Soil Conservation Service Plant Materials Center, Las Lunas, N.M.) were dehulled with a Woodward Laboratory Air-Seed apparatus (Dewald and Beisel 1984). Both whole seeds and dehulled caryopses were used in these trials, but only dehulled caryopses could be adequately sterilized for agar culture studies. Adequate sterilization was provided by immersing the caryopses for 30 seconds in $70 \%$ ethanol, followed by $20 \%$ bleach for 3 minutes. Twenty replicated tubes with 3 seeds each were placed in continuous light $\left(21\right.$ watts $\left./ \mathrm{m}^{2}\right)$ and maintained at $25^{\circ} \mathrm{C}$.

Hormones used included IAA, IBA, and NAA at 0.01, 0.1, 0.25, 0.5 , and $1.0 \mathrm{ppm} ; \mathrm{GA}_{3}$ at 0.25 and $0.5 \mathrm{ppm}$; and combinations of IAA and $\mathrm{GA}_{3}$. All hormones were taken up in a small amount of ethanol, then diluted to the desired concentration with water or MS nutrient solution.

\section{Seed Pretreatment with Hormones}

For planting in soil, any introduction of auxins must occur before the seeds are planted. If seeds are soaked only in an auxin solution, imbibition of water will be so rapid that insufficient auxin will be taken up before germination begins. To slow the rate of imbibition, an osmoticum can be added; for these studies polyethylene glycol (PEG), average molecular weight $6,000-8,000$, was used. Solutions for $-0.25 \mathrm{MPa}$ at $25^{\circ} \mathrm{C}$ (Michel and Kaufman 1973) were prepared and mixed with IAA to $1.0 \mathrm{ppm}$. Slight changes from - $0.25 \mathrm{MPa}$ were investigated, but seemed to have no significant differences from this mixture as long as at least the approximate concentration of PEG was used. Caryopses were soaked for about 4 hours until initial signs of germination were observed on a few caryopses; all caryopses were then removed from the solution.

\section{Greenhouse Studies}

For the greenhouse studies, 4 treatments were used:

(1) hormone and PEG-treated caryopses, sown dry

(2) hormone and PEG-treated caryopses, sown wet

(3) caryopses soaked in water, then sown dry

(4) whole seeds soaked in water, then sown dry

The experimental design was a randomized complete block with 10 replications. Preliminary trials indicated the preferred hormone treatment to be $1.0 \mathrm{ppm}$ IAA in a solution of PEG at $-0.25 \mathrm{MPa}$. For treatment (1), caryopses were soaked in solution for about 4 hours, then air dried at room temperature. For treatment (2), caryopses were soaked as for (1), then sown wet. For treatments (3) and (4), caryopses and whole seeds, respectively, were soaked in water only, then dried before sowing. The greenhouse pots were 11 $\times 11 \times 11 \mathrm{~cm}$, and contained $500 \mathrm{gm}$ fine sandy loam soil. Each pot was subirrigated with $200 \mathrm{gm}$ water. Each pot was sown with 20 seeds or caryopses, and the seeds were covered with $1 \mathrm{~cm}$ fine sand. Each pot was covered with a transparent plastic film to hasten germination; the film was removed at the 2-leaf stage. After 20 days, plants were removed from the pots and the soil washed from the root system. Measurements at this time included (1) shoot length, (2) internode length, (3) primary root length, (4) total adventitious root length, and (5) number of adventitious roots per plant.

\section{Field Plot Design}

The plot layout for the field study was a split-plot design with 10 main blocks. Main effects were:

(1) untreated whole seed, no water injection
(2) untreated whole seed, water injection

(3) untreated caryopses, no water injection

(4) untreated caryopses, water injection

(5) hormone-treated caryopses, no water injection

(6) hormone-treated caryopses, water injection

Caryopsis treatment was applied as described above for the greenhouse studies. Seeds and caryopses were applied by hand into $1-\mathrm{cm}$ furrows, then covered with soil. For water injection, $100-\mathrm{ml}$ water per meter of row was injected with a pressure sprayer.

Each 3-m row was split, with $1 \mathrm{~m}$ of the row randomly selected as a subplot to test the effect of a chemical mulch. Coherex (a petroleum hydrocarbon in water emulsion) was applied at a ratio of 1:6 in water. The application rate was about $0.23 \mathrm{l}$ applied to a $10-\mathrm{cm}$ band along the $1-\mathrm{m}$ row. Measurements in the field study included (1) number of days to emergence, (2) number of tillers per plant, (3) shoot length, (4) number of adventitious roots, (5) adventitious roots length, and (6) shoot dry weight. For each treatment within each block, 5 established plants were examined in detail on 19 September.

\section{Results}

\section{Culture Trials}

All concentrations of NAA inhibited both primary and adventitious root growth. At lower concentrations IBA promoted primary roots but inhibited adventitious roots. IAA promoted adventitious root growth, but inhibited primary root growth. $\mathrm{GA}_{3}$ used alone inhibited adventitious root growth, but promoted primary root growth. Mixtures of $0.5 \mathrm{ppm} \mathrm{GA} 3$ with $1.0 \mathrm{ppm}$ IAA gave the best response in terms of both adventitious and primary root growth. However, the interesting aspect of these trials, from the point of view of potential field use, was the stimulation of adventitious roots by $1.0 \mathrm{ppm}$ IAA, and this treatment was used in subsequent studies.
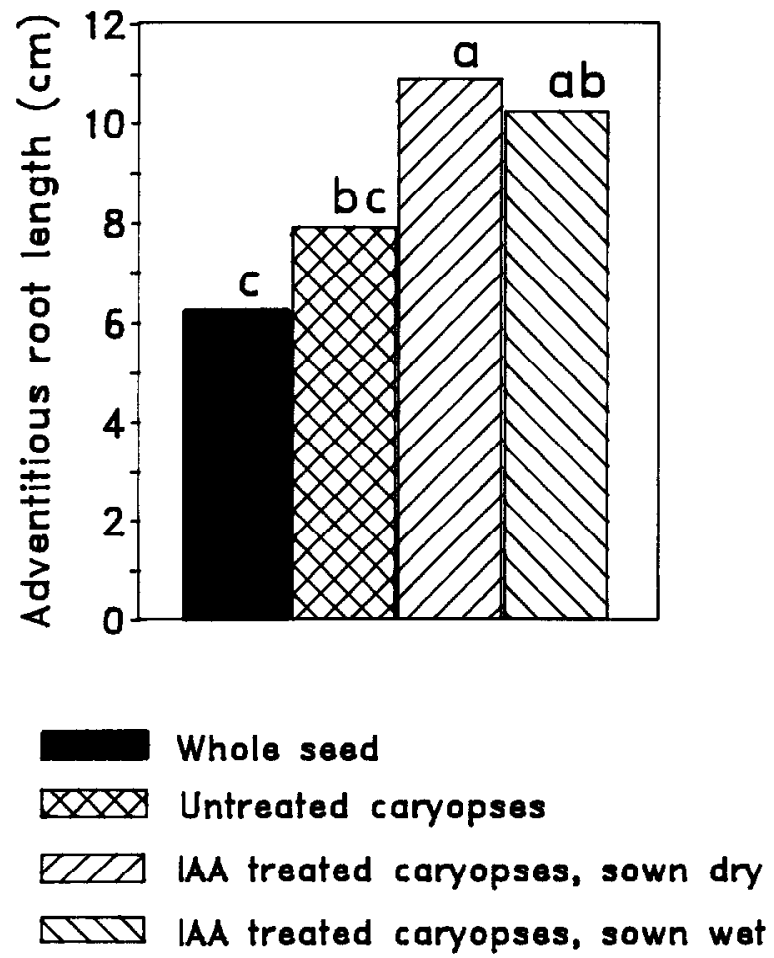

Fig. 1. Adventitious root length of blue grama seedlings grown in the greenhouse after dehulling and IAA pretreatment. Values with different letters differ significantly at $p=0.01$ according to Duncan's multiple range test. 

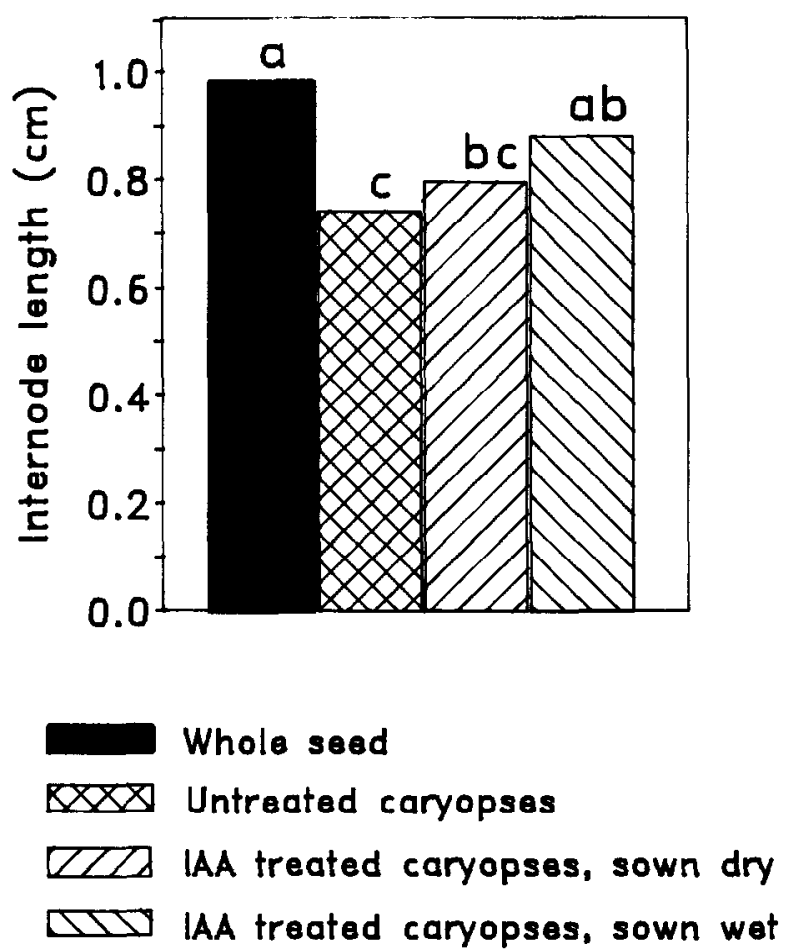

Fig. 2. Subcoleoptile length of blue grama seedlings grown in the greenhouse after dehulling and IAA pretreatment. Values with different letters differ significantly at $\boldsymbol{p}=\mathbf{0 . 0 1}$ according to Duncan's multiple range test.

\section{Greenhouse Studies}

Shoot length, primary root length and number of adventitious roots per plant were not different among the treatments tested. However, adventitious root length (Fig. 1) and internode length (Fig. 2) did vary by treatment.

For adventitious roots, each additional step in treatment intensity had an additional effect on root length. Dehulling plus hormone treatment resulted in increased adventitious root length. Drying the caryopses after hormone treatment slightly increased the measured root length. The internode length was shortest with the dehulling treatment.

\section{Field Studies}

Statistical examination of all measurements indicated that mulch $\times$ main effect interactions were negligible, thus the results for main effects are presented separately from mulch effects. For those variables that showed statistically different responses to main effects, the responses were separated into water injection effect and seed treatment effects.

Dehulling and hormone treatments had beneficial effects in terms of reducing the number of days to shoot emergence (Fig. 3), increasing the number of tillers per plant (Fig. 4), increasing the number of adventitious roots at harvest (Fig. S), and increasing adventitious root length (Fig. 6). The hormone treatment appeared to be additive to the dehulling treatment for these responses. Water injection reduced the number of days to emergence, and increased the number of adventitious roots and number of tillers per plant at harvest time. These treatments did not influence the shoot length nor the shoot dry weight.

The chemical mulch treatments resulted in significantly poorer performance than the unmulched treatments for days to emergence, number of tillers, shoot weight, and number of roots (Table $1)$.

The treatment differences indicated above were primarily apparent during early stages of development triggered by rainfall events of
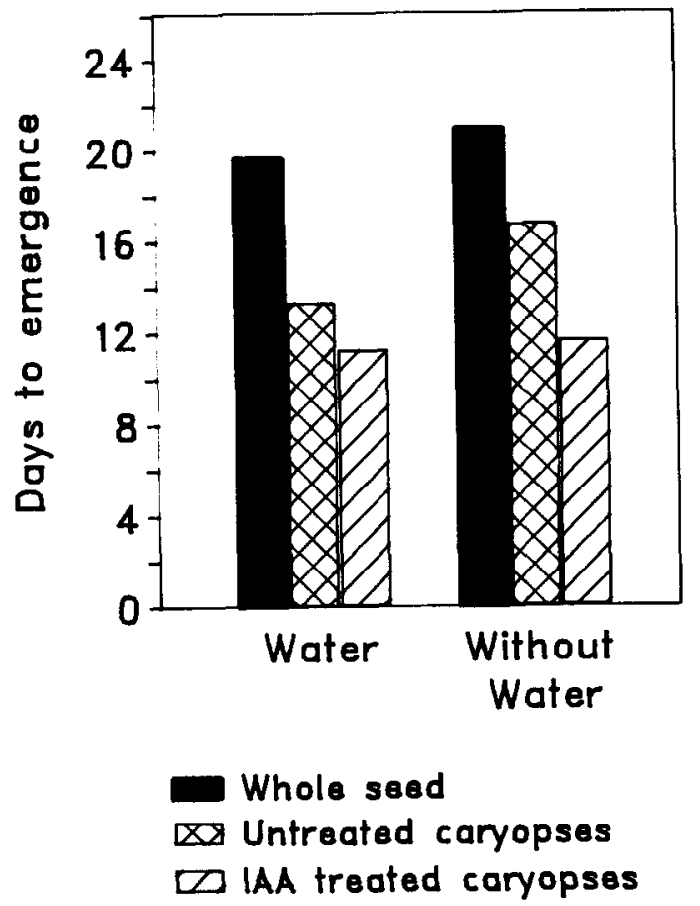

Fig. 3. Number of days to shoot emergence in the field of blue grama seedlings after dehulling and IAA pretreatment (differences significant at $(p<.01)$, with and without water injection $(p<.05)$.
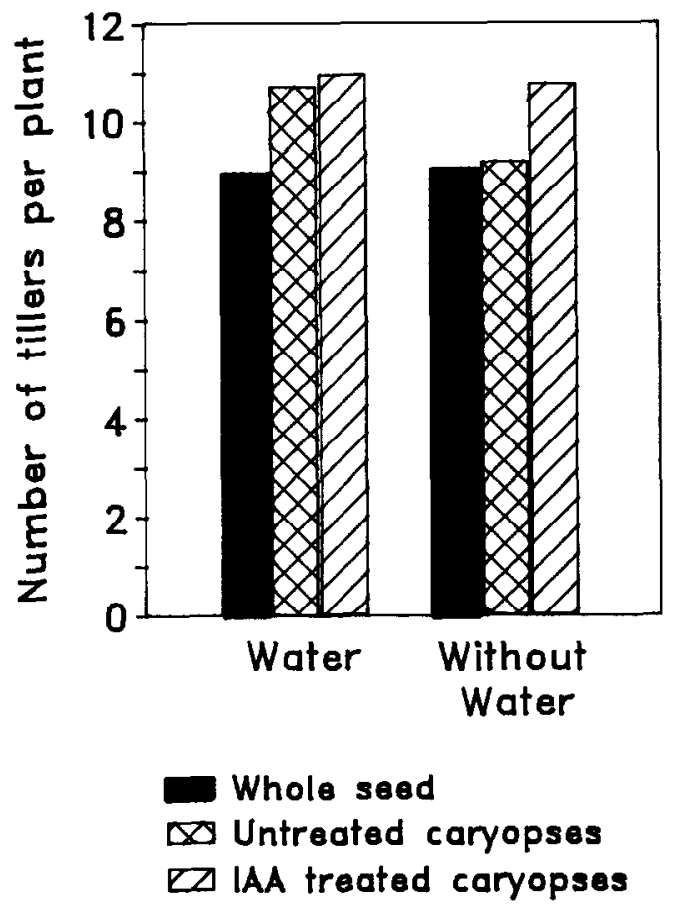

Fig. 4. Number of tillers per plant of blue grama seedlings in the field after dehulling and IAA pretreatment (differences significant at $p<.01$ ), with and without water injection $(p<.05)$.

$0.75,0.6,0.05,2.15$, and $0.13 \mathrm{~cm}$ between the sowing date of 15 June 1989 , and mid-July. Five days after the first rainfall event on 25 June $(0.75 \mathrm{~cm})$, coleoptiles from IAA pretreated caryopses emerged. Coleoptiles from untreated caryopses emerged after the second rainfall event on $4 \mathrm{July}(0.6 \mathrm{~cm})$, and coleoptiles from whole seed did not emerge until after the $2.15-\mathrm{cm}$ rainfall on $8 \mathrm{July}$. No further precipitation occurred until a $0.13-\mathrm{cm}$ event in early 

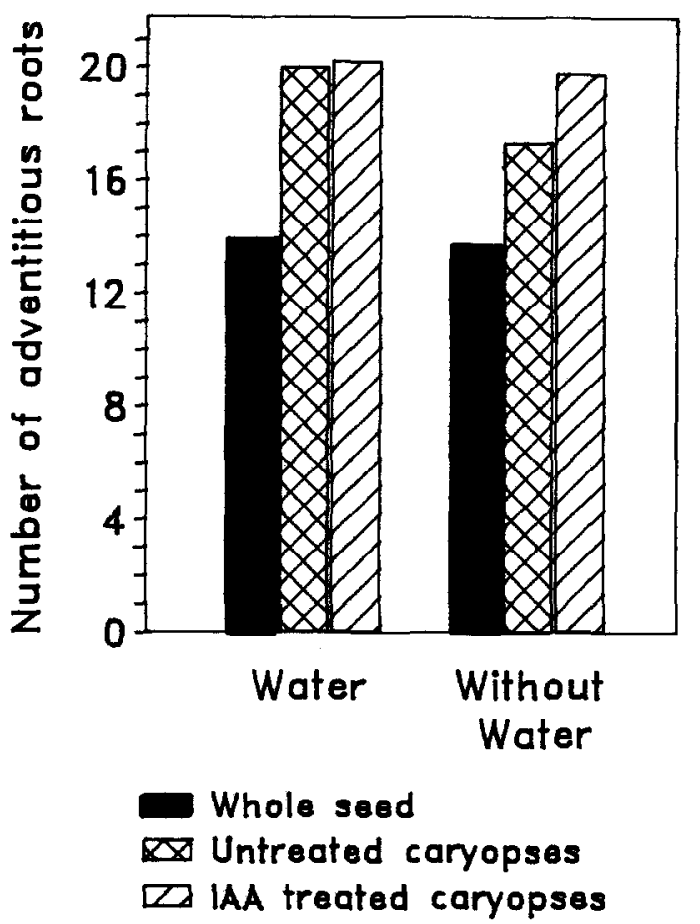

Fig. 5. Number of adventitious roots per plant of blue grama seedlings in the first $5 \mathrm{~cm}$ of soil after dehulling and IAA pretreatment (differences significant at $p<.01$ ), with and without water injection $(p<.05)$.
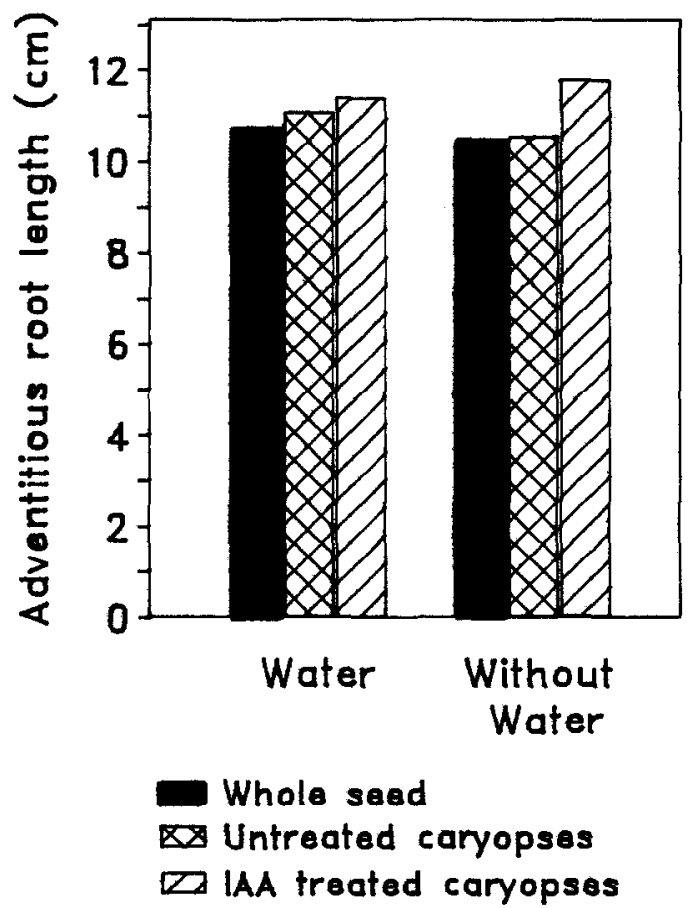

Fig. 6. Length of adventitious roots of blue grama seedlings in the field after dehuling and IAA pretreatment (differences significant at $p<.05$ ), with and without water injection.

August. By late autumn the differences between treatments had diminished.

\section{Discussion and Conclusions}

The time interval between planting and development of the 3-leaf stage in blue grama seedlings is typically a few weeks; under usual range conditions, this also means that adventitious roots are
Table 1. Response of blue grama seedlings to chemical mulch treatments under field conditions.

\begin{tabular}{lcc}
\hline \hline Measured response & $\begin{array}{c}\text { Chemical } \\
\text { mulch }\end{array}$ & Unmulched \\
\hline Time to first emergence (days) $* *$ & 17.1 & 15.6 \\
Number of tillers ** & 9.2 & 10.0 \\
Number of adventitious roots ** & 16.1 & 17.5 \\
Shoot weight $(\mathrm{gm})$ & .54 & .66 \\
\hline
\end{tabular}

* Indicates significant difference, $p<.01$

- Indicates significant difference, $p<.05$

initiated mostly in dry soil, and seedling mortality results. The dehulling and hormone treatments investigated in this study resulted in decreased time to germination, increased adventitious root length, and increased number of tillers per plant. Both hormone (IAA) treatment and dehulling improved seedling performance, and the effect of the hormones appeared to be additive to the effect of dehulling. Hormone treatment without dehulling was not tested because of the difficulty of applying hormone treatments to large quantities of whole seeds. Although these treatments have not yet been investigated under a variety of marginal field conditions, it can be expected that these plant responses should result in improved probabilities of establishment for blue grama seedlings.

In the greenhouse studies, where planting depth could be more carefully controlled than in field experiments, the subcoleoptile length from dehulled caryopses was reduced from the $1-\mathrm{cm}$ control values to about $0.7-0.8 \mathrm{~cm}$. Because earlier results (Roohi et al. 1991) showed the dominant effect of light on subcoleoptile development, this result was unexpected, and we were unable to come up with a consistent explanation based on physiological behavior. Apparently the growing root system was able to elevate the naked caryopses slightly $(2-3 \mathrm{~mm})$ into the covering sand layer, but the whole seeds were held in place at the original $1-\mathrm{cm}$ sowing depth.

Mulch treatments resulted in decreased performance as indicated by all of the variables observed. This is in contrast to results presented by Bement et al. (1961). We do not have a suggested reason for these differences.

\section{Literature Cited}

Bement, R.E., D.F. Hervey, A.C. Everson, and L.O. Hylton, Jr. 1961. Use of asphalt-emulsion mulches to hasten grass seedling establishment. J. Range Manage. 14:102-109.

Bradford, K.J., C.A. Argerich, P. Dahad, O. Somasco, A. Tarqui, and G.E. Welbaum. 1988. Seed enhancement and seed vigor. In: Proc. Internat. Conference on Stand Establishment for Horticultural Crops. Lancaster, Pa., April 27-29, 1988.

Coffin, D.P., and W.K. Lauenroth. 1990. A gap dynamics simulation model of succession in a semiarid grassland. Ecol. Modelling 49:229-266.

Dewald, C.L., and A. Beisel. 1984. Woodward laboratory air-seed shucker for rapid quality determination of chaffy seeds. p. $26 \mathrm{In}$ : Vegetative rehabilitation and equipment workshop, 38th Annu. Rep. USDA Forest Serv., Washington, D.C.

Hauser, V.L. 1986. Water injection in grass seed furrows. Trans. ASAE 29:1247-1253.

Hegarty, T.W., 1978. The physiology of seed hydration and dehydration, and the relation between water stress and the control of germination: a review. Plant Cell Environ. 1:101-119.

Heydecker, W., J. Higgins, and Y.J. Tumer. 1975. Invigoration of seeds? Seed Sci. Technol. 3:881-888.

Hyder, D.N. 1974. Morphogenesis and management of perennial grasses in the United States, p. 89-98. In: Proc. Workshop of the U.S.-Australia Rangeland Panel. Berkeley, Calif., 29 March-5 April 1971. USDA Misc. Pub. 1271.

Mascarenhas, A.F., M. Pathak, R.R. Hendre, D.D. Ghugale, and V. Jagannathan. 1975a. Tissue cultures of maize, wheat, rice and sorghum. IV. Studies of organ differentiation in tissue cultures of maize, wheat and rice. Indian J. Exp. Biol. 13:116-119. 
Mascarenhas, A.F., M. Pathak, R.R. Hendre, and V. Jagannathan. 1975b. Tissue cultures of maize, wheat, rice and sorghum. I. Initiation of viable callus and root cultures. Indian J. Exp. Biol. 13:103-107.

Masteller, V.J., and D.J. Holden. 1970. The growth of and organ formation from callus tissue of sorghum. Plant Physiol. 45:362-364.

Mjichel, B.E., and M.R. Kaufmann. 1973. The osmotic potential of polyethylene glycol 6000. Plant Physiol. 51:914-916.
Murashige, T and F. Skoog. 1962. A revised medium for rapid growth and bioassay with tobacco tissue culture. Physiol. Plant. 15:473-497.

Nakano, H., T. Tashiro, and T. Maeda. 1975. Plant differentiation in callus tissue induced from immature endosperm of Orizia sativa L. Z. Pflanzenphysiol. 76:444-449.

Roohi, R., D.A. Jameson, and N. Nemati. 1991. The effect of light on adventitious root formation in blue grama. J. Range Manage. 44:184-185. 